\title{
What matters for the scalability of prejudice reduction programs and interventions?
}

Wing Hsieh ${ }^{1 *}$, Rebecca Wickes ${ }^{2}$ and Nicholas Faulkner ${ }^{1}$

\footnotetext{
${ }^{1}$ BehaviourWorks Australia, Monash Sustainable Development Institute, Monash University, Melbourne, Australia

${ }^{2}$ School of Social Sciences, Monash University, Melbourne, Australia

* Corresponding author

Email: wing.hsieh@monash.edu
} 


\begin{abstract}
In many countries, policy makers and practitioners turn to prejudice reduction programs and interventions to tackle prejudice in the community. However, successfully addressing prejudice requires an effective intervention that can scale to match the broad span of the problem. Drawing from the experience of 16 prejudice reduction experts from multiple sectors including NGOs, private, government and academia, we developed a scalability assessment framework of criteria that are important for the successful scaling of prejudice interventions. For prejudice reduction interventions, contextual factors are key considerations for successful scaling. We then applied that framework to exemplars of prejudice reduction interventions published in the academic literature. Applying the empirically developed framework to actual interventions demonstrated that for interventions to be effective and scalable, a greater focus on approaches beyond face-to-face contact is required.
\end{abstract}

Keywords: prejudice, scaling, scalability, social science programs, intervention design 


\section{Introduction}

Over the last six decades, prejudice reduction interventions have attempted to reduce prejudice and discrimination across a range of settings (1). The extent to which these initiatives actually reduce prejudice in real-world field settings is mixed (1-3).

Furthermore, very little is known about whether these interventions can be scaled to reach broad populations. Following several high-profile incidents of prejudice and discrimination, there is a clear desire for interventions that have real world impact. However, academic research has placed considerable focus on what works in laboratory settings to the exclusion of what works and is scalable in the field.

For prejudice reduction programs to have widespread impact, they must be scalable and effective in changing prejudicial attitudes and discriminatory behaviour. The scaling of interventions brings its own set of challenges. What works in a specific setting may not work in a wider community intervention (4). Despite the advances in scalability in other fields such as health, what is scalable in the context of prejudice reduction interventions is under-researched. While general theoretical explorations of scaling of social science programs can be informative (5), prejudice reduction interventions warrant specific consideration because of the distinct, complex, and often highly politicised, stakeholder networks. Without understanding what specifically makes a prejudice reduction intervention scalable, efforts to tackle prejudice are not optimised and the reach of interventions remain limited.

This article provides an examination of the considerations for the successful scaling of prejudice reduction interventions and programs. Using a structured method to obtain consensus from expert stakeholders representing academics, not-for-profit, private and public sectors, this paper provides an original framework for successful 
scaling of prejudice reduction interventions. This framework comprehensively covers the relevant considerations for scaling to help those working in prejudice reduction to think through whether an intervention is likely to scale. Further, it also applies as factors that need to be addressed in order to give an intervention the best opportunity for scaling.

In what follows, we describe the current scalability literature and reiterate the need for investigation specific to prejudice reduction. Then we outline our qualitative Delphi method approach used to seek insights from relevant experts on successful scaling of prejudice reduction interventions, which in turn informs our prejudice reduction scalability framework. Finally, we apply the framework to some published prejudice reduction interventions tested in the field under "gold standard" randomised control trial conditions. We demonstrate the implications of applying scalability assessment to popular prejudice reduction approaches for the reach and impact of those interventions and consequences for the future direction of research in prejudice reduction.

\section{Literature Review}

Few studies have examined scalability in social sciences, though recently scholars have begun to develop the theoretical tools necessary to scale up interventions in field settings. The recent work of Al-Ubaydli et al (6) is an excellent example of a holistic approach to scaling social science research in the real world. The model AlUbaydli and colleagues proposed pointed to three main barriers to scalability in small-scale, successful interventions: inference, representativeness of the population, and representativeness of the situation $(5,6)$. First, the authors suggest that there may be issues with the reliability of the evidence, due to the lack of replication of the 
effects, insufficient power in the studies, and incorrect interpretation of the p-value of results. Second, the experimental population may not be generalisable or representative of the broader population. This could arise if recruitment is conducted to either reduce costs or maximise effect size, rather than represent the wider population. Other reasons for lack of representativeness included selection bias, nonrandom compliance and attrition, or diseconomies of scale such that costs are higher at scale. Finally, Al-Ubaydli et al. (6) argue that intervention success may be entirely dependent on the particular context. For example, it could be harder to manage program fidelity and dosage at scale. Additionally, for those programs successfully scaled, political opposition may limit the program's effectiveness.

The model proposed by Al-Ubaydli et al (6) provides a solid roadmap for thinking about scalability in the social sciences. Yet, a key assumption underpinning this model is rationality - that actors are rational in responding to incentives - which often does not hold true (7). The real world is complex and while theoretical models can provide a framework to understand the issue of scaling, it does not consider the "messiness" of reality (8). According to Supplee and Kane (2009), whether a program scales also depends on a range of additional factors such as leadership, maintenance of relationships, policy windows, financial resources and political promises. They opined that scale up cannot be solely contingent on the quality of evidence.

The messiness of the real world and the possible barriers that (non-rational) behaviour create for the scalable interventions has been noted by other scholars. Drawing from behavioural psychology, McConnell (9) proposed that deliberate effort was required to create universal acceptance by policymakers for using an evidence-based approach to scaling. This is a separate issue from the quality of 
evidence. Consideration is also needed to address the "social validity" of programs and interventions, the social appropriateness of procedures and the social importance of effects. McConnell (9) raised an illustrative example of taking into deliberation "customer preferences", a practice that he believes is more common in business than academia as a way to build social validity of an intervention. These subjective contextual factors are beyond the scope of an economic model but are considered to be very relevant to the success of scaling up.

In the health discipline, several scalability assessments have detailed appropriate strategies for scaling health related interventions that also consider the broader suite of "real world" factors. The health sciences have critically engaged with the concept of scalability in health interventions - both in terms of general principles as well as applied to specific programs (10-15). In general, the scalability assessment frameworks from health sciences contain factors that can be grouped in 4 categories - intervention, delivery, costs and context. Across the four categories, the emphasis of high-level factors varied across the assessments. For example, the high-level factors in the two Milat et al scalability assessments are weighted towards details of the intervention. In contrast, in Zamboni et al (11) the high-level factors are concentrated in the context, covering organisational, community and socio-political context. Table 1 provides a summary of the factors relevant for scalability that are included these models from health science.

\section{[Table 1 about here.]}

The factors that lead to successful scaling of health interventions are potentially linked to those that may be relevant for scaling social science interventions. Yet, no study has considered whether there are important differences that may facilitate or hinder scaling prejudice reduction interventions. A recent meta-analysis of prejudice 
reduction interventions tested in field experiments revealed that not a single study materially considered scalability (16).

There are plausible reasons for differences in scaling between the two disciplines. The settings, actors and broader political contexts that health interventions operate may manifest differently in prejudice reduction interventions. Where many health interventions typically experience bi-partisan support, prejudice reduction initiatives can be politically polarising.

Academic research on prejudice reduction interventions has centred on their effectiveness, not their scalability. This has led to a concentrated focus on initiatives that are grounded in contact theory. However, the scalability of this approach is questionable. Contact is a relatively "high-touch" intervention and recruitment can be difficult as people may be unwilling to meet outgroup members $(17,18)$. To successfully tackle prejudice across communities, a framework for understanding the principles of scalability specifically for prejudice reduction interventions is necessary. To this end, the specific aims of this study were: 1) to define scalability as understood in the context of prejudice reduction interventions and 2) develop a framework for scalability designed for prejudice reduction interventions and 3) demonstrate the application of the framework to several exemplar prejudice reduction interventions.

\section{Method}

This study used a Delphi approach, whereby multiple rounds of data collection were used to gain consensus across a group of experts $(10,19,20)$. The Delphi method uses structured group communication in multiple rounds that enables a group of individuals as a whole to reach consensus on complex problems $(19,21)$. It is a 
particularly useful design when dealing with multiple expert groups who may be difficult to bring together in the one plenary session. This approach was considered suitable for examining the scalability of prejudice reduction where there were many actors such as practitioners, government policy makers, human resource teams in large organisations, and academics, across a few different sectors.

\section{Data collection and analysis}

The data collection approach followed that used by Milat et al. (2013). Two rounds of data collection were used. The first round involved one-on-one semi-structured interviews with experts to explore issues relevant to the topic of scalability. Our prejudice reduction experts (PREs) were asked questions about how they would define scalability, and their experience with scaling programs and interventions. Transcripts of interviews were coded by the lead author into high level themes and a definition of scalability was formed using a thematic analysis approach (22). These high-level themes were reviewed by the PREs in the second-round survey. The feedback from the survey was used to refine the list of factors associated with successful scaling. Following this refinement and further reflection by the authors on how the themes would apply in practice, the themes were organised into the framework presented. Interviews were conducted throughout July to September 2019. This was followed by the survey, sent via email, in October 2019.

Selecting prejudice reduction experts (PREs) to participate PREs were selected based on their experience in prejudice reduction and related programs, interventions or research. Purposive sampling was used to ensure that the PREs represented a variety of key sectors including: government, community organisations, private sector and academia. 
A shortlist of relevant experts was identified by the research team by referring to conference attendance lists, and brainstorming based on personal knowledge and networks. They were invited to participate in the study by the lead author via email or LinkedIn messages. In line with previous Delphi studies, we aimed to recruit around 12-14 experts $(10,23,24)$. Other qualitative studies which used interview based techniques have found that the point of saturation is at 12 participants and that most themes will be revealed at six participants (25).

\section{Ethics approval}

Ethics approval was granted by the [redacted] Ethics Committee (19857).

\section{Application of framework: proof of concept}

To demonstrate the applicability of the framework to actual interventions, we selected three prejudice reduction interventions, which have all been shown to be effective in field settings. These interventions are exemplars. Two of these interventions were based on the frequently researched approach of contact - one is based on in-person contact and the other was a form of electronic contact $(26,27)$. The third intervention was based on a relatively novel approach, perceived variability (28). We have applied a code system that indicated for each criterion in our scalability framework whether the intervention was: $\left(^{*}\right)$ unlikely to meet the criterion; $(* *)$ likely to meet the criterion but may need to consider specifics; or $(* * *)$ very likely to meet the criterion. As this was a hypothetical exercise devoid of a specific context for consideration, the context factors were not able to be assessed. 


\section{Results}

Response rate and PREs

Of the 26 experts approached, 13 agreed to participate. Additional snowball sampling undertaken by PREs resulted in a total of 16 PREs. These PREs came from 11 organisations and included academic researchers in prejudice reduction, racism and social psychology, individuals who delivered prejudice reduction or antidiscrimination training to large organisations, government policy makers and program officers, and practitioners working within community groups (Table 2). Participants were predominantly based in Australia, with only one participant based in the US. In the second-round, a representative from each organisation provided feedback but only 14 out of 16 participants responded (88\%) ( 
Figure 1).

[Table 2 about here.]

[Figure 1 about here.]

\section{Definition of scalability}

In the first-round interviews, PREs were asked for a definition of "scalability". Their responses mostly focused on concepts of reach and impact but also implicitly indicated that the program or intervention needed to be effective as well. Based on these responses, the following definition was proposed:

Scalability is the capacity of programs and interventions, already shown to be effective, to increase in reach and impact.

This definition was tested in the second-round survey with the PREs, particularly to understand how they defined the key terms of "effective", "reach" and "impact". Following the feedback from the second-round and considering that nearly all PREs felt that impact and effectiveness were synonymous, the final definition of scalability was formed:

Scalability is the capacity of programs and interventions to increase in reach and impact.

At a high level, the PREs' view on "impact" could be summed up as "having a concrete and demonstrable effect on people's lives" or in other words "actual change". This could be broken down further into two components. The first was improving key outcomes - the PREs highlighted a need for a measurable change in target outcomes. The target outcomes included changes in behaviour, attitudes, engagement, awareness in the broader community. The second component was degree / effect size, that is the size of the change. 
According to the PREs in this study, reach only mattered if there was impact. The most common type of reach identified by the PREs was the replication of a program with a different target group. This referred to scaling a program to a different state, suburb, school age group, community, council etc, with some adaptations to the new context to fit new target groups. PREs also viewed the increase in take-up of a program within the same group as reach. Examples of this form of reach included additional people signing up to a program with no change in eligibility criteria or more people accessing the same information on a website. This type of reach was particularly relevant to those PREs who had a national target audience. However, there was a dissenting view that suggested that this type of reach is growth rather than scaling because it is the improvement of targeting a program to a primary audience.

\section{Key factors for successful scaling}

The round 1 interviews with PREs revealed insights that were then developed and tested with the same group in the round 2 survey. The feedback received in the round 2 survey focused predominantly on definitions of impact and effectiveness. Other feedback raised specific points of clarification or scope of the proposed themes. No new themes were proposed through round 2 indicating the process had reached consensus.

Based on this approach, we arrived at 10 high level assessment factors which we grouped into intervention, delivery, costs, and context categories (Table 3). 
[Table 3 about here.]

Intervention-related factors

Intervention related factors refer to the design of the prejudice reduction programs and interventions. Each of these are detailed below.

\section{Research use and evidence base}

While the PREs generally agreed that research and evidence should be core in program development, they also indicated that the scaling of research into practice is met with challenges, in particular accessing academic research due the lack of "approachable" format of the research. "Research reports that are 60 pages long are kind of useless... Most people are not going to read that...." To overcome these challenges, many PREs suggested the need for ongoing engagement and collaboration across sectors. This often occurred through practitioners developing an informal network of academic connections.

\section{Effectiveness}

Effectiveness was important, with PREs agreeing there was no point to scaling a program or an intervention that did not demonstrate impact. Yet there was no consensus as to how effectiveness should be determined. Some academic PREs indicated a need to focus research on what works in the field rather than laboratory settings. Practitioner PREs indicated impact and effect sizes of interventions were informally evaluated. The concept of effectiveness appears to be quite variable and does not necessarily align to academic norms on evaluation practices. 
Acceptability to target participants (individual community members or employees)

Multiple PREs noted that it was incredibly important that interventions and programs were framed in a way that was acceptable to its participants. An example raised by several PREs was that often prejudice is linked to conservatism and seen as a form of ignorance. This could make it difficult for individuals to admit to being prejudiced, and lead to them feeling threatened. These feelings of threat can lead program participants to disengage or to opt out altogether. Additionally, participation in an intervention or program could generate fears of reputational damage among organisations if their employees' participation might uncover prejudice. This factor focuses on the views of the participants as opposed to stakeholders who are not directly participating in the intervention.

\section{Format of the intervention}

According the PREs, format choices require a balance between reach and impact. They tended to gravitate towards digital formats, including online training, use of social media and apps, to increase scalability potential.

"When we started to then think about how do we deliver cultural training to the 120,000 people... We're talking about a substantial amount of money that we would never have been approved... So you know at the time online training was, I think, a key sort of training program."

However, others highlighted that digital formats bring a different set of challenges, in particular the challenge of equitable access to technology. Low-income, language, digital literacy and disability access barriers restrict the reach of a digital intervention. For practitioners, digital formats were also thought to have lower 
impact. Many indicated a preference for face-to-face delivery despite it being more resource intensive.

Face-to-face delivery has obvious limitations for scaling. Many PREs noted the difficulty in ensuring program fidelity and quality across multiple locations and multiple trainers. Some PREs argued that too much tailoring can be problematic if it detracts from the essence of the program.

Costs and resourcing

Costs and resourcing were frequently mentioned as key considerations for scalability decisions in the round 1 interviews. Costs often would influence choices on which format to adopt. For example, one PRE indicated that "the online component... that kind of came out of a desire to have training for everyone so to speak, in a costeffective way". The reference to cost-effectiveness was made by a number of PREs, who indicated that successful scaling needed to weigh up the effectiveness of the program or intervention against the costs incurred.

\section{Delivery}

A number of factors related to the implementation of the intervention or program. These included the adaptability of the program, whether there was capacity and feasibility to deliver at scale, and whether the right agreements were in place to support scaling.

\section{Adaptability of program}

PREs indicated that the adaptability of programs and interventions to particular contexts was critical for scaling. PREs noted that although they might design a program based on the evidence of what works, the reality was that programs might not fit the specific context and practical realities that they operated in. For example, a 
program might need to be segmented into smaller blocks so that participants can choose smaller units due to time constraints.

\section{Feasibility of delivery at scale and provider capacity}

Feasibility to implement an intervention at scale was discussed by the PREs. If a key feature of a program included personalised support for members, this may not be feasible at scale as it would exceed a provider's capacity. Additionally, multiple PREs noted that the absence of specific skillsets and significant experience in prejudice reduction across contexts could create a 'natural' limit to scalability. Staff burnout was also viewed as potentially limiting scalability, particularly for contactbased interventions, where minority group staff members meet program participants.

\section{Restrictive or unclear intellectual property (IP) agreements}

Restrictive or unclear IP agreements have placed limits on the ability of some PREs to scale their interventions and programs. In developing interventions collaboratively between academics and practitioners, there were instances where IP agreements did not have the flexibility to adapt and scale the final output or only with the consent of all parties. Where parties did not have the same vision for the scaling of their intervention, joint ownership was restrictive on the future use of the intervention.

\section{Contextual factors}

Context was frequently cited as a key consideration in the round 1 interviews. Nearly all PREs noted the importance of stakeholder buy-in. PREs broadly considered three types of stakeholders: political, organisational and community. General context issues such as social dynamics and cultural, linguistic and other aspects were also raised by the PREs. 


\section{Political stakeholders}

Many PREs from the community and public sectors commented that politicians ultimately make the funding decisions. Political constraints limit what public organisations can effectively achieve in prejudice reduction strategies. Many PREs noted that the role of politics is quite different when it comes to prejudice reduction as it is an issue that attracts significant political partisanship and debate. Political decision-makers do support large scale programs that tackle prejudice and discrimination, but as two PREs mentioned, this is often only after a high-profile racist incident.

\section{Organisational stakeholders}

In the organisational context, the importance of buy-in from managers and executives to the success of scaling prejudice reduction programs was clear:

"One manager in one of them was 'Yeah you should really do [the training]. It's really good... And all of her staff were like 'the training's awesome. It's really cool.' ... The other [manager] was not like that at all. The other one... was like 'oh I don't know why we have to do this. Such a waste of time... it's not like we have [minority staff members and clients]. I don't see a problem... That's how the rest of her staff felt as well."

Having champions for the cause who are relatively senior decision makers and creating awareness of benefits helped organisational leaders to build a case for allocating resources to prejudice reduction strategies. The PREs indicated that it is not enough to understand the importance of prejudice reduction in an operating environment where there are competing priorities. For many organisations, prejudice reduction and similar programs are not core business. According to the PREs, these 
competing priorities can result in limited resources and commitment being allocated to prejudice reduction programs. In the experience of practitioner PREs, a strong reputation could help create trust between the program provider and participants and ensure ongoing demand or interest despite competing priorities.

\section{Community stakeholders}

Community support was viewed as critical for the scaling of prejudice reduction interventions. Consultation and co-design with communities (through community leaders) helped to achieve buy-in. Through consulting and working with communities to understand needs, programs could be designed to fit the context and purpose. In the broader community, role models were noted as helpful, particularly in delivering messages. Some PREs indicated that sporting figures, high profile individuals and members of minority groups could be effective spokespersons for reaching particular segments of the community and delivering messages.

\section{General context}

Prejudice reduction programs and interventions operate in specific social contexts. The PREs noted that the context included cultural, linguistic and religious considerations relevant to a particular community as well as the media narrative, community sentiment and values, and other aspects that create social dynamics of power and norms.

The social dynamics that reflect existing inequalities in society and structural power differences may coincide with the fear of changes in power and privilege and has implications for scalability. According to one PRE,

“...if you come from a model that locates prejudice much more in intergroup relations and also in contexts that has to do with, 'I'm feeling threatened as a 
white person ... by the arrival of immigrants', then it becomes much more complex because that very much depends then on who I am, my power, my relationship to the outgroup, my relationship to the ingroup..."

The majority of PREs agreed that the context of each community differed and addressing these differences encouraged local buy-in. Understanding and adapting to local context (or new target population) was universally considered a critical factor for scalability.

\section{Application of framework to prejudice reduction interventions}

In this section we apply our framework to a selection of prejudice reduction interventions that have been shown to be effective in field settings. We focus on field experiments in our case studies as they represent the strongest form of evidence for what works in real-world settings, which are the environments that scaling will occur in. Experiments have long been used to examine the impact of interventions on prejudice. One of the critical features of an experimental approach is random assignment whereby participants are randomly assigned to receive the "treatment" or to be in a control group because it gives confidence that any difference between the treatment group and the control group is due to the intervention itself, rather than underlying characteristics of the members of the group. This allows causality to be attributed to the intervention. However. interventions that are tested in artificial settings may not necessarily yield the same results in the real world where the context is vastly different (29). For the purposes of designing a prejudice reduction intervention with the goal of real-world scalability, testing in field environments is of much greater interest. Thus, field experiments are considered to be the most probative type evidence of what works to reduce prejudice and was the starting principle for our choice of case studies (1). 
Within the pool of field experiments that aimed to reduce prejudice, we selected three exemplar studies reflecting key aspects of the prejudice reduction literature. Our first case study used a face-to-face contact approach. Contact theory was formalised in the 1950s by Allport and is based on the premise that prejudice between groups can be reduced when members of the two groups meet (30). It is one of the most commonly tested prejudice reduction approaches in field settings (16). Notwithstanding this, it has been recognised that there are limitations to scaling of face-to-face contact interventions as there are a range of difficulties involved in encouraging individuals to engage in intergroup contact (17). In light this the contact literature has electronic forms, which we consider in our second case study. Finally, our third case study used a relatively untested approach of perceived variability - the degree to which an individual views members of the outgroup as heterogeneous (31) - which has been found by some field studies as being highly effective and as outlined in detailed below shows good potential for scalability. Through this exercise we provide a scalability assessment for popular prejudice reduction approaches as well as a novel approach to draw implications for where research efforts should be concentrated to best tackle prejudice at scale.

Example 1: Face-to-face contact intervention (26)

This intervention centred on a class exchange program where primary school students from Israeli-Jewish schools met with students from Israeli-Palestinian schools. Students in the treatment classes were engaged in activities requiring interaction with students from different backgrounds. This consisted of six 4-hour monthly meetings. The curriculum included sessions aimed at creating awareness of self and others. Meanwhile, the students in the control condition engaged in art activities without any interaction with students from the other group. 
Based on the details provided in the article, there appear to be significant issues with scaling this intervention. Applying the scalability factors, the issues that are likely to arise relate to acceptability of the intervention and physical constraints. Contact is something that is difficult to encourage, in part because it generates anxiety (17). The face-to-face nature of the contact in this intervention and its requirement for active participation could raise issues with acceptability more so than the more detached approach of an electronic text-based contact intervention (discussed next). Furthermore, the requirement for an adequate number of minority group members could lead to physical constraints for scaling of this intervention. The face-to-face format could result in more binding constraints on this factor than compared to an electronic contact format.

A number of scalability factors presented more ambiguous challenges. For example, while in-person meetings are likely to be more resource intensive (e.g. requiring facilitators, meeting rooms etc.), this may not necessarily be the case if appropriate measures were available (e.g. automated booking systems). Thus, costs and resourcing require closer consideration rather than being a clear constraint on scaling. Similarly, the time intensive design of the intervention, requiring a total of 24 hours of participants' time could constrain scaling in a non-school setting. Yet there could be situations where this would not be the case. For example, if an employer decided that tackling prejudice is linked to core business, this could justify the time investment of staff. As there was no information on the factors relating to a particular context, this could not be assessed in this exercise. 


\section{[Table 4 about here.]}

Example 2: Electronic contact intervention (27)

This intervention involved pairing undergraduate students to work together on a project. Majority group students (Israelis from European and Latin American backgrounds) were paired with Israeli-Ethiopian students to interact in three online text-chat sessions to co-develop a travel guide. The design featured electronic contact as its mechanism for influencing prejudice.

Based on the details provided in the article, the intervention met some of the scalability criteria. The intervention design had demonstrated efficacy in the literature as evidenced by a growing body of evidence on electronic contact and prejudice reduction $(32,33)$. However, the time commitment and the degree of interaction required between majority and minority group members, could limit acceptability and adaptability of the intervention to non-student audiences. The intervention required an adequate number of minority group members to pair with which could also constrain scaling.

\section{[Table 5 about here.]}

Example 3: Perceived variability (28)

This intervention comprised a randomised control trial across eight high schools. In the treatment schools, a poster highlighting the diversity of Arabs was put up in classrooms and outside the school principal's office for two weeks. In the control schools, no poster was put up. The mechanism used to reduce prejudice was to increase the perceived variability of Arabs (i.e. the perception that Arabs were a heterogeneous group and that individual Arabs differed from each other on various aspects). 
Based on the details provided in this article, this intervention met most of the criteria required for scalability. The intervention design had demonstrated efficacy in the literature, albeit perceived variability is a relatively new intervention approach and only featured in a handful of studies. The subtle nature of the intervention (i.e. the placement of a poster on the wall) required minimal active engagement on the part of the participant, likely increasing acceptability of the intervention to participants. Further, the poster format was likely to be cost-effective, although scaling to other formats (e.g. billboards, online advertisements) could involve greater costs.

One potential limit for scalability could be the adaptability of the intervention. Given that the underlying approach, perceived variability, is still a relatively untested approach there may be unknown constraints in adapting this intervention to target groups other than Arab Muslims.

[Table 6 about here.]

\section{Discussion}

Through input of PREs in the Delphi process, we have arrived at a definition of scalability specific to prejudice reduction and developed a novel framework for scalability specific to prejudice reduction intervention. These findings make a unique and important contribution to the prejudice reduction literature by identifying the factors that are likely to support (or impede) scalability. In particular, the importance of contextual factors was evident in the framework for scaling prejudice reduction interventions.

The resulting framework for scalability of prejudice reduction interventions can be applied to interventions published in the academic literature to identify interventions with the best likelihood for scaling. We illustrated this through the application of the 
framework developed herein to a number of published interventions. In doing so, we provide further evidence that commonly used prejudice reduction interventions do not meet all criteria for scalability and may have limited utility in reducing prejudice at scale in broad community settings. We discuss each of these findings in turn below.

\section{Context requires careful consideration for successful scaling}

While for the most part, the factors in the prejudice reduction scalability framework are commonly observed in the scaling frameworks in health, the significance of context for scaling prejudice reduction interventions was uniquely apparent. This was in line with the assessment factors of Zamboni et al (11). Context for successful scaling of prejudice reduction interventions goes beyond the delivery-related factors that Al-Ubaydli et al (5) proposed. While they alluded, in passing, that representativeness of the situation may include issues such as political opposition, the examples that they focused on were largely related to delivery - whether the delivery, dosage and program were correct. To successfully scale a prejudice reduction intervention, there is a need for genuine consideration of context, separate from consideration of delivery issues. In our study, the PREs almost universally raised the importance of context or "real-world factors" that a framework grounded in rational economic assumptions would not necessarily include.

Our results from the Delphi process support the view of Supplee and Kane (2020) that contextual factors like leadership, relationships with stakeholders and researchers, timing with political and policy windows - the realities of the policy process - need to be addressed. Indeed, as we consulted PREs beyond the government sector, our results go further to suggest that these are relevant across sectors and not just in the policy context. 


\section{Scalability considerations indicate new directions for prejudice research}

In applying our scalability framework to three exemplar interventions, it was evident that some of the more commonly researched approaches to prejudice reduction are unlikely to scale. Our framework indicated that the intervention based on face-toface contact is likely to confront the most difficulty in scaling because of the practical constraints, and also because in-person contact may be less acceptable to participants than more passive approaches. Even an intervention based on electronic contact may face limitations to scaling due to limitations in access to technology and the required time commitment. Contact is a relatively high touch intervention type as it requires active participation. Thus, recruitment for the intervention could be difficult as people may be unwilling to participate in an intervention that involves meeting adversaries $(17,18)$.

This exercise of applying the framework suggests that from a scalability perspective, interventions that are more subtle and able to be published in media, like those based on perceived variability, are much more likely to have the greatest potential for scaling. These interventions avoid the practical hurdles of contact-based interventions as they do not require active participation - participants are not required to interact with outgroup members. Thus, an intervention using a perceived variability approach is more likely to be acceptable to participants who are predisposed to prejudice.

However, to-date the greatest effort in understanding how to reduce prejudice has focused on contact-based approaches. Reviews of prejudice reduction interventions demonstrate that the prejudice reduction theory most frequently employed in academia and often used in practice is contact theory $(1,30,34)$. As an indication of the vast volume of literature on contact, one of the most comprehensive and 
structured reviews of the contact-prejudice reduction literature located 515 studies, drawing from 713 independent samples, on the effect of intergroup contact (34). This focus on contact has not subsided since that review $(30,35)$.

There has been substantially less research effort on other intervention approaches including those that have greater possibility of scaling. This is problematic because to tackle a problem as pernicious and widespread as prejudice requires interventions that can scale. It is not enough to just know what works or even be the most effective approach. Without the ability to scale, such interventions cannot address the reach of prejudice as a social problem. To broaden the suite of prejudice reduction interventions, research into what works to reduce prejudice needs to expand from contact-based approaches towards intervention approaches that have greater potential to scale.

\section{Limitations}

While there were strengths to the Delphi approach in the development of the scalability framework for prejudice reduction, such as the depth of commentary and expertise that it solicited, this depth did come at a limit to breadth. For this study, we used a small number of PREs, largely Australian - and while our sample size was similar to that in similar studies, we do recognise that this is a limitation. In light of this, we suggest that the next step for our prejudice reduction framework would be to test this framework in real settings with a broad set of users to refine its application across a number of settings.

We also narrowly defined the scope of the study to only prejudice reduction interventions but noticed that many of the factors are quite general. The more general factors could potentially have broader application beyond prejudice reduction into 
other social programs. Future work may consider whether this framework applies to other social programs.

\section{Conclusion}

Using a two-round Delphi process, we developed a framework that has considerations for successfully scaling prejudice reduction interventions, based on the insights and experience of PREs across the discipline. The scalability framework is the first to be developed and applied to prejudice reduction interventions. By identifying the best practice principles for scalability, the framework has applications beyond advancing academic knowledge. These principles provide necessary guidelines to assist policymakers or practitioners in their selection or design of a scalable intervention for reducing prejudice. The framework provides guidance on considerations of practical issues and complements the issues relating to the applicability of the evidence base proposed in theoretical models. In doing so, the framework guides the user to have a better understanding of whether factors that lead to scalability are substantially met. This better understanding of scalability also revealed that more research effort needs to be been placed on prejudice reduction approaches with greater possibility of scaling to better tackle the pervasive problem of prejudice in society. 


\section{References}

1. Paluck EL, Green DP. Prejudice reduction: What works? A review and assessment of research and practice. Annu Rev Psychol [Internet]. 2009;60(1):339-67. Available from: http://www.annualreviews.org/doi/10.1146/annurev.psych.60.110707.163607

2. Bezrukova K, Spell CS, Perry JL, Jehn KA. A meta-analytical integration of over 40 years of research on diversity training evaluation. Psychol Bull. 2016;142(11):1227-74.

3. Chang EH, Milkman KL, Gromet DM, Rebele RW, Massey C, Duckworth AL, et al. The mixed effects of online diversity training. Proc Natl Acad Sci U S A. 2019;116(16):7778-83.

4. Caldwell L. Public and private sector nudgers can learn from each other. Behav Public Policy. 2018;2(2):235-45.

5. Al-Ubaydli O, Lee MS, List JA, Mackevicius C, Suskind D. How Can Experiments Play a Greater Role in Public Policy? 12 Proposals from an Economic Model of Scaling. SSRN Electron J. 2019;(October):1-44.

6. Al-Ubaydli O, List JA, Suskind D. The Science of Using Science: Towards an Understanding of the Threats to Scaling Experiments [Internet]. NBER Working Paper Series. Cambridge MA; 2019. Report No.: 25848. Available from: http://www.nber.org/papers/w25848

7. Jolls C, Sunstein CR, Thaler R. A Behavioural Approach to Law and Economics. Stanford Law Rev. 1998;50(5):1471-550.

8. Supplee LH, Kane MC. The realities of scaling within evidence-based policy. Behav Public Policy. 2020;1-13.

9. Mcconnell S. How can experiments play a greater role in public policy? Three notions from behavioral psychology. Behav Public Policy. 2020;1-10.

10. Milat AJ, King L, Bauman AE, Redman S. The concept of scalability: Increasing the scale and potential adoption of health promotion interventions into policy and practice. Health Promot Int. 2013;28(3):285-98.

11. Zamboni K, Schellenberg J, Hanson C, Betran AP, Dumont A. Assessing scalability of an intervention: Why, how and who? Health Policy Plan. 2019;34(7):544-52.

12. Milat AJ, Newson R, King L, Rissel C, Wolfenden AB, Redman S, et al. A guide to scaling up population health interventions. Public Heal Res Pract. 2016;26(1):1-5.

13. Milat AJ, Bauman A, Redman S. Narrative review of models and success factors for scaling up public health interventions. Implement Sci [Internet]. 2015;10(1):1-12. Available from: http://dx.doi.org/10.1186/s13012-0150301-6

14. Damschroder LJ, Aron DC, Keith RE, Kirsh SR, Alexander JA, Lowery JC. Fostering implementation of health services research findings into practice: A 
consolidated framework for advancing implementation science. Implement Sci. 2009;4(1):1-15.

15. Barker PM, Reid A, Schall MW. A framework for scaling up health interventions: Lessons from large-scale improvement initiatives in Africa. Implement Sci [Internet]. 2016;11(1):1-11. Available from: http://dx.doi.org/10.1186/s13012-016-0374-x

16. Hsieh W, Faulkner N, Wickes R. What reduces prejudice in the real world? A meta-analysis of prejudice reduction field experiments. 2020. (Manuscript submitted for publication).

17. Paolini S, Harwood J, Hewstone M, Neumann DL. Seeking and avoiding intergroup contact: Future frontiers of research on building social integration. Soc Personal Psychol Compass. 2018;1-19.

18. Pettigrew TF, Tropp LR, Wagner U, Christ O. Recent advances in intergroup contact theory. Int J Intercult Relations [Internet]. 2011;35(3):271-80. Available from: http://dx.doi.org/10.1016/j.ijintrel.2011.03.001

19. Linstone HA, Turoff M. Introduction. In: Linstone HA, Turoff M, editors. The Delphi Method - Techniques and Applications. Addison-Wesley; 1975. p. 116.

20. de Meyrick J. The Delphi method and health research. Health Educ. 2003;103(1):7-16.

21. Skulmoski GJ, Hartman FT, Krahn J. The Delphi Method for Graduate Research. J Inf Technol Educ. 2007;6.

22. Braun V, Clarke V. Thematic analysis. In: APA handbook of research methods in psychology, Vol 2: Research designs: Quantitative, qualitative, neuropsychological, and biological. 2012. p. 57-71.

23. Kokko S, Kannas L, Villberg J. The health promoting sports club in Finland A challenge for the settings-based approach. Health Promot Int. 2006;21(3):219-29.

24. Bergmann E, Marshall M, Mattke S, Klazinga N, Mainz J, Leatherman S, et al. OECD Health Care Quality Indicator Project. The expert panel on primary care prevention and health promotion. Int J Qual Heal Care.

2006;18(suppl_1):21-5.

25. Guest G, Bunce A, Johnson L. How Many Interviews Are Enough? Field methods. 2005;18(1):59-82.

26. Berger R, Abu-Raiya H, Gelkopf M. The Art of Living Together: Reducing Stereotyping and Prejudicial Attitudes through the Arab-Jewish Class Exchange Program (CEP). J Educ Psychol [Internet]. 2015 Aug;107(3):67888. Available from:

https://search.proquest.com/docview/1773220697?accountid=12528

27. Abu-rayya HM. Majority members ' endorsement of the acculturation integrationist orientation improves their outgroup attitudes toward ethnic minority members : An electronic-contact experiment. Comput Human Behav [Internet]. 2017;75:660-6. Available from: 
http://dx.doi.org/10.1016/j.chb.2017.06.010

28. Er-rafiy A, Brauer M. Modifying perceived variability: four laboratory and field experiments show the effectiveness of a ready-to-be-used prejudice intervention. J Appl Soc Psychol [Internet]. 2013 Apr;43(4):840-53. Available from: https://search.proquest.com/docview/1433108845?accountid=12528

29. Levitt SD, List JA. Viewpoint: On the generalizability of lab behaviour to the field. Can J Econ. 2007;40(2):347-70.

30. Paluck EL, Green SA, Green DP. The contact hypothesis re-evaluated. Behav Public Policy [Internet]. 2019;3(2):129-58. Available from: https://www.cambridge.org/core/terms.https://doi.org/10.1017/bpp.2018.25Do wnloadedfromhttps://www.cambridge.org/core.

31. Brauer M, Er-rafiy A. Increasing perceived variability reduces prejudice and discrimination. J Exp Psychol. 2011;47:871-81.

32. White FA, Abu-Rayya HM. A dual identity-electronic contact (DIEC) experiment promoting short- and long-term intergroup harmony. J Exp Soc Psychol [Internet]. 2012;48(3):597-608. Available from: http://dx.doi.org/10.1016/j.jesp.2012.01.007

33. White FA, Abu-Rayya HM, Weitzel C. Achieving twelve-months of intergroup bias reduction: The dual identity-electronic contact (DIEC) experiment. Int J Intercult Relations [Internet]. 2014;38(1):158-63. Available from: http://dx.doi.org/10.1016/j.ijintrel.2013.08.002

34. Pettigrew TF, Tropp LR. A meta-analytic test of intergroup contact theory. $\mathbf{J}$ Pers Soc Psychol. 2006;90(5):751-83.

35. Paluck EL, Porat R, Clark CS, Green DP. Prejudice Reduction: Progress and Challenges. Annu Rev Psychol. 2021;72:1-28.

36. Milat AJ, Lee K, Conte K, Grunseit A, Wolfenden L, Nassau F Van, et al. Intervention Scalability Assessment Tool : A decision support tool for health policy makers and implementers. 2020;2:1-17. 


\section{Tables and figures}

Table 1: Comparison of health scalability assessment frameworks

\begin{tabular}{|c|c|c|c|}
\hline High-level & Milat et al. (10) & Milat et al. (36) & Zamboni et al. (11) \\
\hline Intervention & $\begin{array}{l}\text { Effectiveness, } \\
\text { adoption and reach } \\
\text { - Evaluation approach }\end{array}$ & 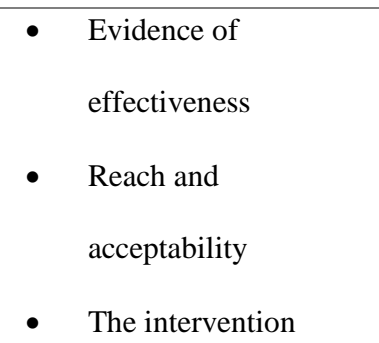 & $\begin{array}{l}\text { - Attributes of the } \\
\text { innovation / } \\
\text { intervention }\end{array}$ \\
\hline Delivery & $\begin{array}{l}\text { - Intervention delivery } \\
\text { - Workforce, technical } \\
\text { and organisational } \\
\text { resources required }\end{array}$ & $\begin{array}{ll}\text { - } & \text { Fidelity and adoption } \\
\text { - } & \text { Delivery setting and } \\
\text { - } & \text { Imorkforce } \\
& \text { inflementation } \\
\text { infrastructure }\end{array}$ & $\begin{array}{l}\text { - Scale-up strategy } \\
\text { - Attributes of the } \\
\text { implementers }\end{array}$ \\
\hline Costs & - Cost considerations & $\begin{array}{l}\text { Intervention costs and } \\
\text { benefits }\end{array}$ & 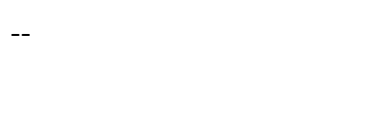 \\
\hline Context & - Contextual factors & $\begin{array}{l}\text { - Strategic and political } \\
\text { context }\end{array}$ & $\begin{array}{l}\text { - } \quad \text { Supportive } \\
\text { organisational culture } \\
\text { and leadership } \\
\text { - Attributes of } \\
\text { adopting community } \\
\text { Socio-political } \\
\text { context }\end{array}$ \\
\hline Other & -- & $\begin{array}{l}\text { - } \quad \text { The problem } \\
\text { - Sustainability }\end{array}$ & -- \\
\hline
\end{tabular}


Table 2: PREs by organisation type

\begin{tabular}{lcc}
\hline Organisation type & Total PREs $(\mathbf{n}=\mathbf{1 6})$ & $\begin{array}{c}\text { Number of } \\
\text { organisations }\end{array}$ \\
\hline Government & 7 & 4 \\
Community practitioners & 4 & 3 \\
Academic & 3 & 2 \\
Non-government & 2 & 2 \\
\hline
\end{tabular}


Figure 1 : Delphi process

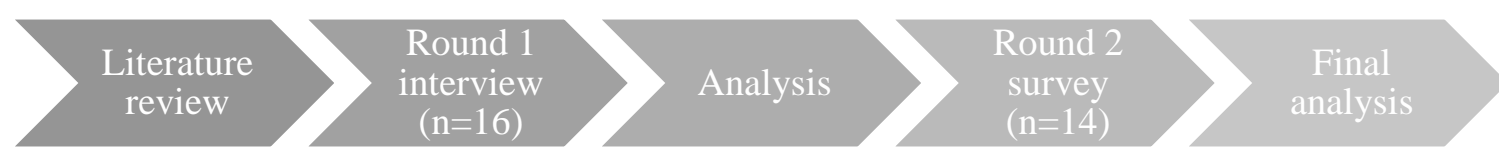


Table 3: Framework of scalability criteria for prejudice reduction interventions
Category
Theme
Sub-theme
Detail or example

\begin{tabular}{|c|c|c|c|}
\hline \multirow[t]{4}{*}{ Intervention } & $\begin{array}{l}\text { Research and } \\
\text { evidence use }\end{array}$ & $\begin{array}{l}\text { Application of } \\
\text { research and evidence } \\
\text { in intervention - } \\
\text { evidence-based design }\end{array}$ & Access to evidence \\
\hline & Effectiveness & $\begin{array}{l}\text { Impact of the } \\
\text { intervention on } \\
\text { prejudice }\end{array}$ & $\begin{array}{l}\text { Variable approach to } \\
\text { effectiveness }\end{array}$ \\
\hline & Acceptability & $\begin{array}{l}\text { Level of engagement } \\
\text { and acceptability with } \\
\text { target audience }\end{array}$ & $\begin{array}{l}\text { Tailoring to } \\
\text { participant needs }\end{array}$ \\
\hline & Format & $\begin{array}{l}\text { Suitability of format } \\
\text { based on capabilities, } \\
\text { costs and target } \\
\text { audience }\end{array}$ & Online vs in-person \\
\hline Costs & Costs and resourcing & Funding constraints & $\begin{array}{l}\text { Source of funding and } \\
\text { resources identified } \\
\text { and cost effectiveness }\end{array}$ \\
\hline \multirow[t]{3}{*}{ Delivery } & $\begin{array}{l}\text { Feasibility and } \\
\text { provider capacity }\end{array}$ & $\begin{array}{l}\text { Internal physical } \\
\text { constraints on scaling }\end{array}$ & Staff capacity at scale \\
\hline & Legal & $\begin{array}{l}\text { Intellectual property } \\
\text { constraints on scaling }\end{array}$ & Terms of collaboration \\
\hline & Adaptability & $\begin{array}{l}\text { Adaptability of } \\
\text { intervention to specific } \\
\text { context and practical } \\
\text { realities }\end{array}$ & Tailoring required \\
\hline \multirow[t]{4}{*}{ Context } & \multirow[t]{3}{*}{ Stakeholder buy-in } & Political stakeholders & High profile events \\
\hline & & Organisational & $\begin{array}{l}\text { Cause champions / } \\
\text { leaders and } \\
\text { organisational } \\
\text { imperatives; provider } \\
\text { reputation }\end{array}$ \\
\hline & & $\begin{array}{l}\text { Community } \\
\text { stakeholders }\end{array}$ & Role models \\
\hline & General context & Societal dynamics & $\begin{array}{l}\text { Intergroup conflict, } \\
\text { language, sentiment }\end{array}$ \\
\hline
\end{tabular}




\begin{tabular}{|c|c|c|c|c|}
\hline Category & & Theme & Code & Comments \\
\hline \multirow[t]{4}{*}{ Intervention } & 1 & $\begin{array}{l}\text { Research and evidence } \\
\text { use }\end{array}$ & $* * *$ & Draws from contact literature \\
\hline & 2 & Effectiveness & $* * *$ & $\begin{array}{l}\text { Relatively effective among contact studies, extensive literature on } \\
\text { contact - likely to have been replicated but need to confirm }\end{array}$ \\
\hline & 3 & Acceptability & $*$ & $\begin{array}{l}\text { Difficulties may arise in encouraging participants to meet; time } \\
\text { commitment required unlikely to be acceptable outside of school } \\
\text { environment }\end{array}$ \\
\hline & 4 & Format & $* *$ & Time and labour intensive \\
\hline Costs & 5 & Costs and resourcing & $* *$ & $\begin{array}{l}\text { Depends on logistics required for meeting, requires closer } \\
\text { consideration }\end{array}$ \\
\hline \multirow[t]{3}{*}{ Delivery } & 6 & $\begin{array}{l}\text { Feasibility and provide } \\
\text { capacity }\end{array}$ & $*$ & $\begin{array}{l}\text { In person contact and requirement for minority members creates } \\
\text { physical constraints; potential difficulty in maintaining program } \\
\text { fidelity }\end{array}$ \\
\hline & 7 & Legal & $* * *$ & Intervention details accessible via publication \\
\hline & 8 & Adaptability & $* *$ & Difficult to adapt outside of school context \\
\hline \multirow[t]{2}{*}{ Context } & 9 & Stakeholder buy-in & - & This will be specific to actual context \\
\hline & 10 & General context & - & This will be specific to actual context \\
\hline
\end{tabular}


Table 5: Application of framework to Abu-rayya (2017)

\begin{tabular}{|c|c|c|c|c|}
\hline Category & & Criterion & Code & Notes \\
\hline \multirow[t]{4}{*}{ Intervention } & 1 & $\begin{array}{l}\text { Research and evidence } \\
\text { use }\end{array}$ & $* * *$ & Draws from research literature \\
\hline & 2 & Effectiveness & $* * *$ & $\begin{array}{l}\text { Effective results reported, extensive literature on contact - but less } \\
\text { in online settings }\end{array}$ \\
\hline & 3 & Acceptability & $* *$ & $\begin{array}{l}\text { Intervention tested in a number of countries; may be difficult to } \\
\text { implement outside of school environment; significant time } \\
\text { requirement; electronic contact may be more acceptable than in } \\
\text { person }\end{array}$ \\
\hline & 4 & Format & $* *$ & $\begin{array}{l}\text { May not scale outside of school environment, significant time } \\
\text { requirement }\end{array}$ \\
\hline Costs & 5 & Costs and resourcing & $* *$ & $\begin{array}{l}\text { Leverages common technology e.g. video conferencing or text chat } \\
\text { but requires digital access; relatively effective intervention in non- } \\
\text { face-to-face contact category; similar to typical school curriculum } \\
\text { so costs likely to be considered reasonable }\end{array}$ \\
\hline \multirow[t]{3}{*}{ Delivery } & 6 & $\begin{array}{l}\text { Feasibility and provide } \\
\text { capacity }\end{array}$ & $* *$ & $\begin{array}{l}\text { Requires an adequate number of minority group members to pair } \\
\text { up in exercise }\end{array}$ \\
\hline & 7 & Legal & $* * *$ & Intervention details accessible via publication \\
\hline & 8 & Adaptability & $* *$ & $\begin{array}{l}\text { Good potential to adapt contents to other contexts - however, may } \\
\text { be difficult to adapt outside of school environment due to nature of } \\
\text { tasks }\end{array}$ \\
\hline \multirow[t]{2}{*}{ Context } & 9 & Stakeholder buy-in & - & This will be specific to actual context \\
\hline & 10 & General context & - & This will be specific to actual context \\
\hline
\end{tabular}


Table 6: Application of framework to Er-rafiy and Brauer (2013)

\begin{tabular}{l|r|l|l|l|}
\multicolumn{2}{|c}{ Category } & \multicolumn{2}{l}{ Theme } & Nodes \\
\hline \multirow{4}{*}{ Intervention } & 1 & $\begin{array}{l}\text { Research and evidence } \\
\text { use }\end{array}$ & $* * *$ & Draws from contact literature \\
\cline { 2 - 5 } & & & Effectiveness & $\begin{array}{l}\text { Large effect size relative to other prejudice reduction field } \\
\text { experiments - however, theoretical approach is based on limited } \\
\text { studies }\end{array}$ \\
\cline { 2 - 5 } & 3 & Acceptability & $* * *$ & $\begin{array}{l}\text { Subtle intervention, poster on wall likely to be acceptable as it does } \\
\text { not require active engagement }\end{array}$ \\
\cline { 2 - 5 } Costs & 4 & Format & $* * *$ & Poster-based intervention likely to be easy to scale \\
\hline \multirow{3}{*}{ Delivery } & 5 & Costs and resourcing & $* * *$ & $\begin{array}{l}\text { Likely to require minimal cost due to poster format but scaling to } \\
\text { advertising boards could require further costs. }\end{array}$ \\
\cline { 2 - 5 } & 6 & $\begin{array}{l}\text { Feasibility and provide } \\
\text { capacity }\end{array}$ & $* * *$ & Poster format likely to be easy to scale and maintain fidelity \\
\cline { 2 - 5 } & 7 & Legal & $* * *$ & Intervention details accessible via publication \\
\hline \multirow{2}{*}{ Context } & 8 & Adaptability & $* *$ & $\begin{array}{l}\text { Relatively untested approach - current studies do not consider } \\
\text { effectiveness beyond Arab-Muslims }\end{array}$ \\
\cline { 2 - 5 } & 9 & Stakeholder buy-in & - & This will be specific to actual context \\
\cline { 2 - 5 } & 10 & General context & - & This will be specific to actual context \\
\hline
\end{tabular}

